\title{
Prognosis of Newborn Infants with Hypoxic- Ischemic Brain Injury Assessed by Phosphorus Magnetic Resonance Spectroscopy
}

\author{
D. AZZOPARDI, J. S. WYATT, E. B. CADY, D. T. DELPY, J. BAUDIN, A. L. STEWART, \\ P. L. HOPE, P. A. HAMILTON, AND E. O. R. REYNOLDS \\ Departments of Paediatrics [D.A., J.S.W., J.B., A.L.S., P.L.H., P.A.H., E.O.R.R.], and Medical Physics and \\ Bioengineering [E.B.C., D.T.D.], University College and Middlesex School of Medicine, London, England
}

\begin{abstract}
To investigate the prognostic significance of abnormalities of oxidative phosphorylation, the brains of 61 newborn infants born at $27-42$ wk of gestation and suspected of hypoxic-ischemic brain injury were examined by surface-coil phosphorus magnetic resonance spectroscopy. Of these infants, 23 died, and the neurodevelopmental status of the 38 survivors was assessed at 1 y of age. Of the 28 infants whose phosphocreatine/inorganic orthophosphate $(\mathrm{PCr} / \mathrm{Pi})$ ratios fell below $95 \%$ confidence limits for normal infants, 19 died, and of the nine survivors, seven had serious multiple impairments (sensitivity $74 \%$, specificity $92 \%$, positive predictive value for unfavorable outcome $93 \%$ ). Of the 12 infants with ATP/total phosphorus ratios below 95\% confidence limits 11 died (sensitivity $47 \%$, specificity $97 \%$, positive predictive value $91 \%$ ). Among the 46 infants with increased cerebral echodensities, $\mathrm{PCr} / \mathrm{Pi}$ was more likely to be low, and prognosis poor, in infants whose echodensities were diffuse or indicated intraparenchymal hemorrhage than in infants whose echodensities were consistent with periventricular leukomalacia. We conclude that when reduced values for $\mathrm{PCr}$ / $\mathrm{Pi}$ indicating severely impaired oxidative phosphorylation are found in the brains of infants suspected of hypoxicischemic injury, the prognosis for survival without serious multiple impairments is very poor, and that when ATP/ total phosphorus is reduced, death is almost inevitable. (Pediatr Res 25:445-451, 1989)
\end{abstract}

\section{Abbreviations}

${ }^{31} \mathrm{P}$ MRS, phosphorus magnetic resonance spectroscopy $\mathrm{PCr}$, phosphocreatine

$\mathrm{Pi}$, inorganic orthophosphate

PME, phosphomonoester

PDE, phosphodiester

total $\mathbf{P}$, total mobile phosphorus

$\mathrm{pH}_{\mathrm{i}}$, intracellular $\mathrm{pH}$

BE, base excess

SDS, standard deviation score

GQ, Griffiths general quotient

PVL, periventricular leukomalacia

\footnotetext{
${ }^{31} \mathrm{P}$ MRS can be used to measure, noninvasively, the relative concentrations of phosphorus metabolites that are involved in

Received September 13, 1988; accepted December 8, 1988.

Address for correspondence and reprint requests Prof. E.O.R. Reynolds, Department of Paediatrics, UCMSM, The Rayne Institute, 5 University Street, London, WClE 6JJ, England.

Supported by the DHSS, MRC, Wellcome Trust, and Action Research for the Crippled Child.
}

energy metabolism in the brain tissue of newborn infants $(1,2)$. $\mathrm{pH}_{\mathrm{i}}$ can also be estimated.

In previous investigations, we found that abnormalities indicating abnormal oxidative phosphorylation were detectable in the brain after birth asphyxia (3) and in the presence of cerebral echodensities detected by ultrasound that are associated with various forms of hypoxic-ischemic brain injury (4). In the latter study, it was shown that evidence of severely abnormal oxidative phosphorylation was related to subsequent loss of brain tissue. The purpose of the present investigation was to explore the prognostic significance of abnormalities of oxidative phosphorylation for survival and for neurodevelopmental status at $1 \mathrm{y}$ of age in a group of infants suspected of hypoxic-ischemic brain injury.

\section{MATERIALS AND METHODS}

Infants. Sixty-one infants were studied. Evidence or suspicion of hypoxic-ischemic brain injury was based on the presence of one or more of the following findings: 1) BE of less than -15 $\mathrm{mM} /$ liter in umbilical cord arterial blood or in arterial blood obtained shortly after delivery or after a postnatal asphyxial episode; 2) such abnormal neurologic signs as hypotonia, abnormal movements, or seizures; 3 ) increased cerebral echodensities as demonstrated with a Diasonics Sonotron (Bedford, England) DS1 sector scanner with 6- and 7.5-MHz probes: the abnormalities included diffusely increased echodensities often associated with birth asphyxia, marked periventricular echodensities suggestive of PVL, and very dense echodensities indicating intraparenchymal hemorrhage (5). The principal reason for entry to the study was birth asphyxia in 40 infants, postnatal asphyxia in five, and increased echodensities in 16 . Table 1 gives clinical data for each of these groups of infants, as well as for the total of 61 infants.

This study was approved by the University College London Committee on the Ethics of Human Experimentation and informed parental consent was obtained.

$M R S .{ }^{31} \mathrm{P}$ MRS was carried out as previously described using an Oxford Research Systems (Oxford, England) TMR 32-200 spectrometer and a surface coil to acquire spectra from the infants' adjacent cerebral hemisphere-mainly from the temporoparietal cortex (6). The transport system used enabled the infants to be monitored and, if necessary, mechanically ventilated during the investigation, which usually took $30-45 \mathrm{~min}$. In infants with unilateral or unequal cerebral lesions, as detected by ultrasound, both hemispheres or the hemisphere most severely affected was studied. Sedation was not required specifically for the studies, though 38 of the 61 infants were being treated with anticonvulsants, normally phenobarbitone. Data processing and analysis were as described elsewhere (6); phosphorus metabolite ratios were calculated from the integrals of the gated spectral peaks after correction for the effects of saturation, and $\mathrm{pH}_{\mathrm{i}}$ was 
estimated from the difference in resonance frequency between $\mathrm{PCr}$ and $\mathrm{Pi}(7)$.

The initial MRS studies were performed 0-6 (median 2) d after the known or presumed time of the hypoxic-ischemic episode or, in infants studied principally because of an abnormal ultrasound scan, within 0-6 (median 3) d of the first detection of increased echodensities. In 47 of the 61 infants, studies were repeated at intervals of $0-16$ (median 2 ) d. The total number of MRS studies performed on the 61 infants was 169 (median 2, range $1-6$, in each infant). Measurements of arterial or transcutaneous oxygen and carbon dioxide tensions, $\mathrm{pH}, \mathrm{BE}$, blood pressure, and blood glucose concentration made in unstable or ill infants shortly before and/or after the time when the studies were carried out gave values within or close to normal ranges except in three terminally ill infants with values for BE of -16 to $-18 \mathrm{mmol} / \mathrm{liter}$.

Follow-up. The 38 surviving infants were enrolled into a neurodevelopmental follow-up clinic for repeated examinations. At 49-67 (median 53) wk of age, corrected for preterm birth, a full clinical and neurologic assessment was carried out as previously described (8), including a Griffiths test (9) by an independent observer. Outcome was classified into four groups as follows: normal: no demonstrable impairment; minor impairments: disorders of tone or reflexes not causing disability; major neuromotor impairments: isolated neuromotor impairments causing disability; multiple major impairments: more than one disabling impairment, including neuromotor, neurosensory (visual or hearing), neurobehavioral, and psychometric, often together with microcephaly.

Detailed autopsies were carried out on nine of the 23 infants who died.

\section{RESULTS}

Figure 1 shows typical sequences of ${ }^{31} \mathrm{P}$ spectra from the brains of two infants who sustained extremely severe birth asphyxia. Characteristic peaks can be seen and are assigned as follows: 1 , PME; 2, Pi; 3, PDE; 4, PCr; 5, 6, and 7, the $\gamma, \alpha$, and $\beta$ phosphorus nuclei of nucleotide triphosphate-mainly ATP (6). Both infants had normal spectra and values for $\mathrm{pH}_{\mathrm{i}}$ on the 1 st $\mathrm{d}$ of life as judged by comparison with data from infants with normal brains (6). Later, abnormalities developed: $\mathrm{PCr} / \mathrm{Pi}$ fell, and $\mathrm{pH}_{\mathrm{i}}$ tended to rise. In one of the infants (Fig. 1a), ATP/total $\mathrm{P}$ also fell, and he died aged $60 \mathrm{~h}$ with evidence of deteriorating oxidative phosphorylation. The phosphorus metabolite ratios returned to normal in the other infant (Fig. $1 b$ ), but he died later, aged $27 \mathrm{~d}$, with severe cerebral atrophy.

Table 2 shows metabolite ratios and $\mathrm{pH}_{\mathrm{i}}$ at the time when the values for $\mathrm{PCr} / \mathrm{Pi}$ were at their lowest. Data are given for the whole population of 61 infants and, as in Table 1, according to the principal reason for enrollment in the study. For comparison, data from a concurrently studied control group of 30 preterm and term infants with normal brains, and of whom full details are given elsewhere (6) are also shown. Because it has been found that some of the metabolite ratios, notably $\mathrm{PCr} / \mathrm{Pi}$, change with increasing maturation of the brain (6), SDS, corrected for gestational plus postnatal age, comparing data from the study and control infants were also calculated. The results are given in Table 3 as mean values $\pm \mathrm{SD}$, but because some of the data were nonnormally distributed, statistical comparisons were made using the Mann-Whitney test. Table 3 shows that several of the metabolite ratios, including $\mathrm{PCr} / \mathrm{Pi}, \mathrm{PCr} /$ total $\mathrm{P}$, and $\mathrm{ATP} /$ total $\mathrm{P}$ were significantly less in the study infants than in the controls, and that $\mathrm{Pi} /$ total $\mathrm{P}$ and $\mathrm{Pi} / \mathrm{ATP}$ were correspondingly higher.

Figure 2 shows the relation between the minimum values recorded for $\mathrm{PCr} / \mathrm{Pi}$ in each infant, survival, and neurodevelopmental outcome. Infants who were found to be progressing normally or with minor impairments at 1 y had neonatal values
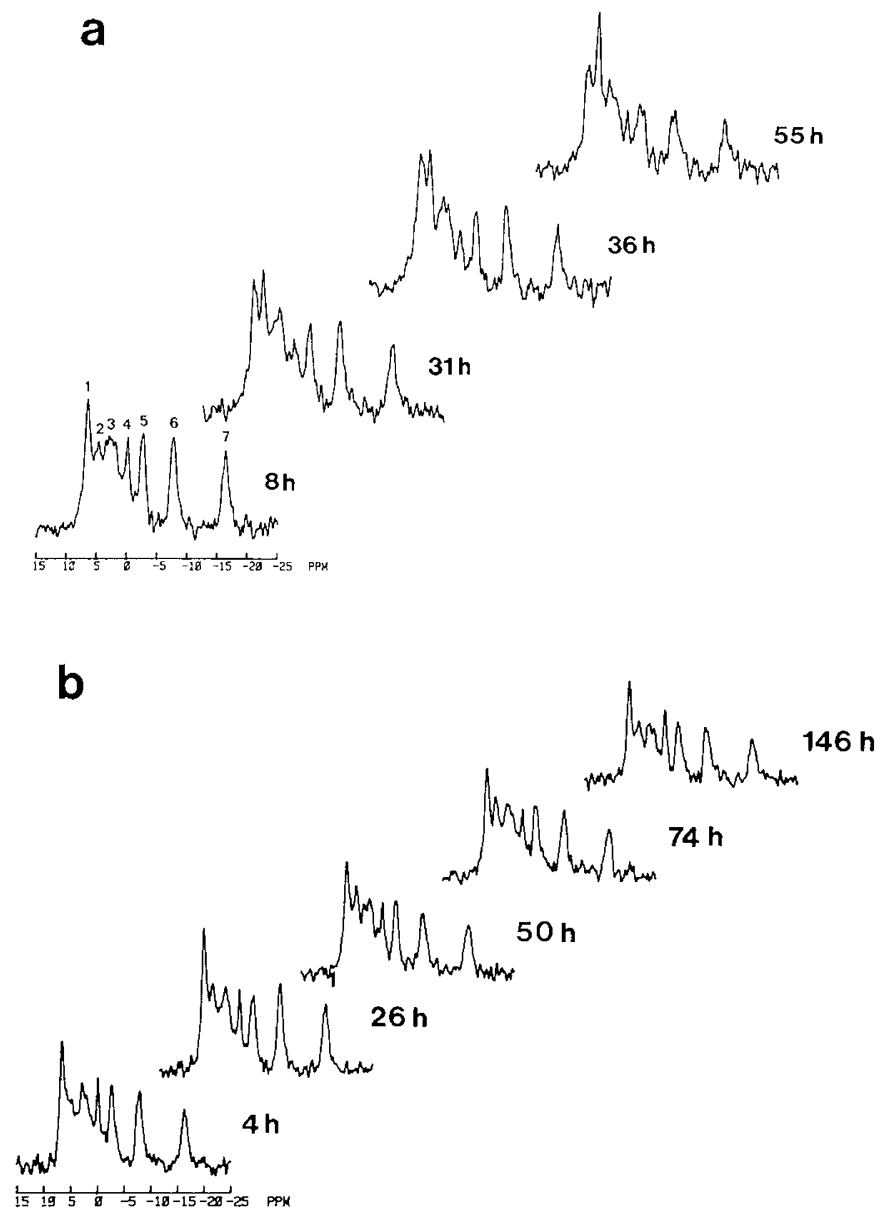

Fig. 1. ${ }^{31} \mathrm{P}$ spectra from two birth-asphyxiated infants born at 37 and 36 wk of gestation: postnatal ages at the time of study are indicated. $a$, peak assignments (numbers 1-7) are given in text. At $8 \mathrm{~h}, \mathrm{PCr} / \mathrm{Pi}$ was 0.99 , ATP/total $\mathrm{P}$ was 0.09 , and $\mathrm{pH}_{\mathrm{i}}$ was 7.06: $\mathrm{pH}_{\mathrm{i}}$ rose to a maximum of 7.28 at $36 \mathrm{~h}$. Minimum value for $\mathrm{PCr} / \mathrm{Pi}$ was 0.32 at $55 \mathrm{~h}$, when ATP/ total $\mathrm{P}$ was 0.04 and $\mathrm{pH}_{\mathrm{i}}$ was 6.99 . The infant died aged $60 \mathrm{~h} . b$, at $4 \mathrm{~h}$ $\mathrm{PCr} / \mathrm{Pi}$ was 0.97 , ATP/total $\mathrm{P}$ was 0.09 , and $\mathrm{pH}_{\mathrm{i}}$ was $7.08: \mathrm{pH}_{\mathrm{i}}$ rose to a maximum of 7.23 at $26 \mathrm{~h}$. Minimum value for $\mathrm{PCr} / \mathrm{Pi}$ was 0.65 at $50 \mathrm{~h}$, but by $146 \mathrm{~h}$ it was normal, 0.93 . ATP/total $\mathrm{P}$ never fell below normal. The infant died aged $27 \mathrm{~d}$ with cerebral atrophy.

for $\mathrm{PCr} / \mathrm{Pi}$ that were within or close to $95 \%$ confidence limits for the control infants (Fig. $2 a$ ), whereas values for infants with multiple and, to a lesser extent, isolated major neuromotor, impairments were often low (Fig. 2b). Most infants who died had $\mathrm{PCr} / \mathrm{Pi}$ values below $95 \%$ confidence limits (Fig. 2c) Death was regarded as wholly or largely attributable to cerebral injury except in one infant, born at $27 \mathrm{wk}$ of gestation, who died of necrotizing enterocolitis.

Figure 3 gives data for ATP/total P. The only difference found between study infants and controls was that values below confidence limits were almost always associated with subsequent death. Figure 4 shows the relation between the SDS of the PCr/ Pi ratio and the GQ in the survivors.

In the nine infants on whom autopsies were performed, very severe widespread hypoxic-ischemic damage was found. The minimum recorded values for $\mathrm{PCr} / \mathrm{Pi}$ in these infants were between 0.16 and 0.73 (median 0.28 ) and for ATP/total P, 0.02 and 0.12 (median 0.08).

In addition to the 16 infants studied primarily because of increased echodensities, another 30 infants studied because of birth asphyxia were also found to have increased echodensities, giving a total of 46 infants in the study groups as a whole. The 
Table 1. Clinical details*

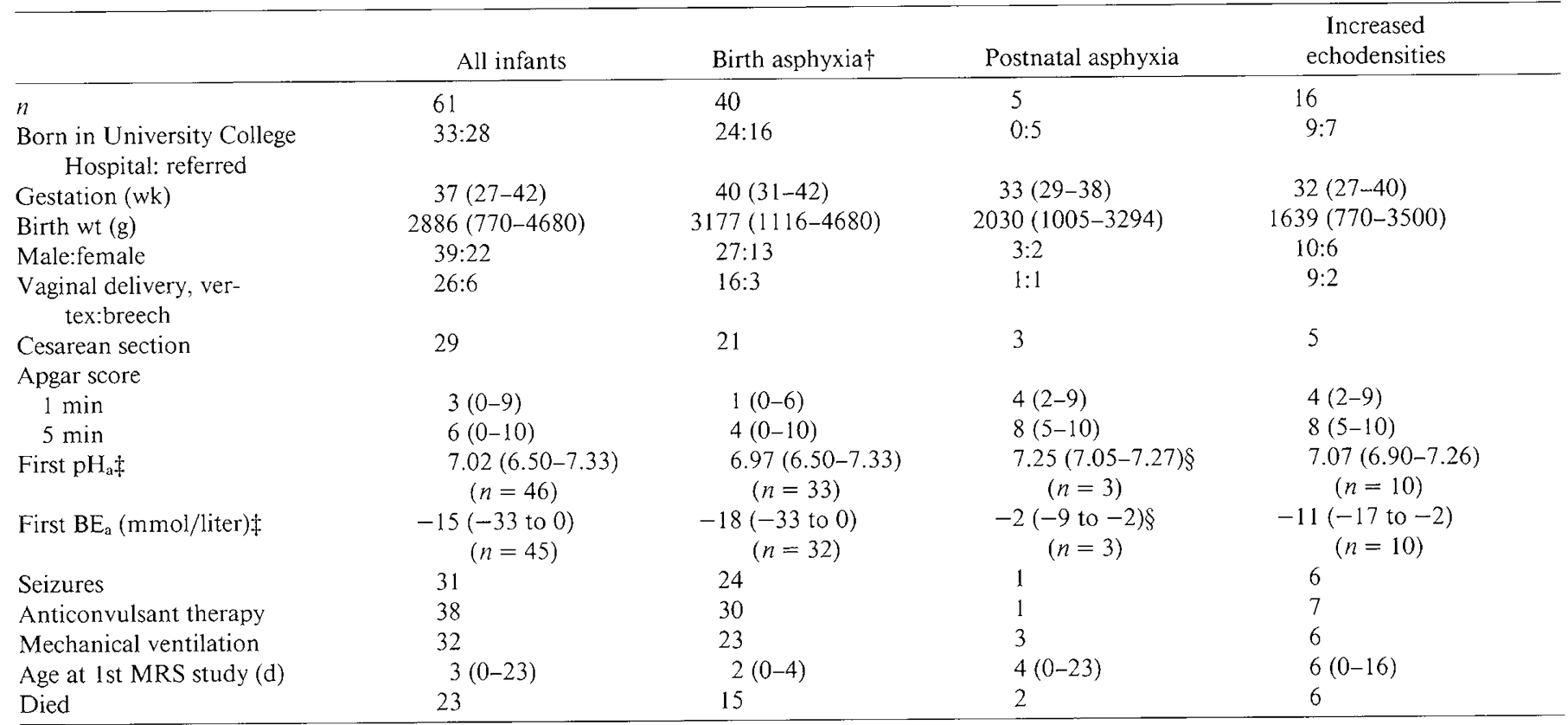

* Values are numbers of infants or medians and ranges.

† Of the 40 infants, 34 had fetal distress as defined by abnormal cardiotocograms and/or the passage of meconium: three of the six other infants had placental abruption, and in seven of the 40 infants the second stage of labor lasted more than $1 \mathrm{~h}$.

$\mp$ From cord blood in nine infants and arterial blood within $4 \mathrm{~h}$ (usually within $1 \mathrm{~h}$ ) of delivery in 37.

$\S$ Values within $3 \mathrm{~h}$ after the asphyxial episode were, for $\mathrm{pH}_{\mathrm{a}} 7.12(6.38-7.27)$, and for $\mathrm{BE}_{\mathrm{a}}-20(-13$ to -30$) \mathrm{mmol} / \mathrm{liter}(n=5)$.

Table 2. Phosphorus metabolite ratios and $\mathrm{pH}_{i}$ in normal infants and infants suspected of hypoxic-ischemic brain injury*

\begin{tabular}{|c|c|c|c|c|c|}
\hline & \multirow[b]{2}{*}{$\begin{array}{l}\text { Normal infants } \\
\quad(n=30)\end{array}$} & \multicolumn{4}{|c|}{ Infants suspected of hypoxic-ischemic brain injury } \\
\hline & & $\begin{array}{l}\text { All infants } \\
(n=61)\end{array}$ & $\begin{array}{l}\text { Birth asphyxia } \\
\quad(n=40)\end{array}$ & $\begin{array}{l}\text { Postnatal asphyxia } \\
(n=5)\end{array}$ & $\begin{array}{c}\text { Increased } \\
\text { echodensities } \\
(n=16)\end{array}$ \\
\hline Gestation (wk) & $33(26-42)$ & $38(27-42)$ & $41(31-42)$ & $33(31-38)$ & $33(27-41)$ \\
\hline Age (d) & $5(1-96)$ & $3(1-23)$ & $3(1-10)$ & $5(4-23)$ & $9(3-16)$ \\
\hline $\mathrm{PCr} / \mathrm{Pi}$ & $0.99 \pm 0.18$ & $0.69 \pm 0.35$ & $0.67 \pm 0.35$ & $1.04 \pm 0.20$ & $0.61 \pm 0.32$ \\
\hline ATP/total P & $0.09 \pm 0.01$ & $0.08 \pm 0.03$ & $0.08 \pm 0.03$ & $0.10 \pm 0.02$ & $0.08 \pm 0.03$ \\
\hline $\mathrm{PCr} /$ total P & $0.09 \pm 0.01$ & $0.08 \pm 0.02$ & $0.08 \pm 0.02$ & $0.10 \pm 0.01$ & $0.07 \pm 0.03$ \\
\hline $\mathrm{Pi} /$ total $\mathrm{P}$ & $0.10 \pm 0.01$ & $0.15 \pm 0.09$ & $0.16 \pm 0.10$ & $0.10 \pm 0.01$ & $0.16 \pm 0.10$ \\
\hline $\mathrm{PME} /$ total P & $0.29 \pm 0.03$ & $0.29 \pm 0.04$ & $0.29 \pm 0.04$ & $0.27 \pm 0.02$ & $0.31 \pm 0.05$ \\
\hline $\mathrm{PDE} /$ total P & $0.20 \pm 0.02$ & $0.20 \pm 0.03$ & $0.20 \pm 0.03$ & $0.22 \pm 0.01$ & $0.19 \pm 0.03$ \\
\hline $\mathrm{PCr} / \mathrm{ATP}$ & $1.02 \pm 0.20$ & $1.16 \pm 0.63$ & $1.21 \pm 0.68$ & $1.06 \pm 0.18$ & $1.07 \pm 0.03$ \\
\hline $\mathrm{Pi} / \mathrm{ATP}$ & $1.05 \pm 0.23$ & $5.22 \pm 18.75$ & $3.28 \pm 4.48$ & $1.05 \pm 0.29$ & $11.36 \pm 36.44$ \\
\hline PME/ATP & $3.18 \pm 0.61$ & $6.60 \pm 17.90$ & $4.62 \pm 2.89$ & $2.97 \pm 0.68$ & $12.96 \pm 34.73$ \\
\hline PDE/ATP & $2.21 \pm 0.48$ & $3.87 \pm 7.27$ & $3.26 \pm 2.38$ & $2.35 \pm 0.47$ & $5.89 \pm 13.81$ \\
\hline $\mathrm{pH}_{\mathrm{i}} \dagger$ & $\begin{array}{c}7.11 \pm 0.13 \\
(n=22)\end{array}$ & $\begin{array}{c}7.14 \pm 0.27 \\
\quad(n=55)\end{array}$ & $\begin{array}{c}7.16 \pm 0.19 \\
(n=36)\end{array}$ & $\begin{array}{c}7.09 \pm 0.14 \\
\quad(n=5)\end{array}$ & $\begin{array}{l}7.13 \pm 0.45 \\
(n=14)\end{array}$ \\
\hline
\end{tabular}

* Values are those obtained when $\mathrm{PCr} / \mathrm{Pi}$ was at its lowest. Medians and ranges, or means $\pm \mathrm{SD}$, are given.

$\uparrow \mathrm{pH}_{\mathrm{i}}$ was not calculated in some of the infants because the resolution of the Pi peak was judged to be inadequate.

echodensities were diffuse in 26 of the 46 infants, they were regarded as characteristic of PVL in 11 and of intraparenchymal hemorrhage in 9 (all of whom also had intraventricular hemorrhage) (5). The relation between the type of echodensities, $\mathrm{PCr} /$ $\mathrm{Pi}$ and outcome is given in Figure 5. When the echodensities were diffuse, most values for $\mathrm{PCr} / \mathrm{Pi}$ were low and the prognosis was very bad (Fig. 5a): only three infants-whose values for $\mathrm{PCr} / \mathrm{Pi}$ were normal-survived with no or only minor impairments. Echodensities thought to be due to PVL were usually associated with $\mathrm{PCr} / \mathrm{Pi}$ values that were within $95 \%$ confidence limits, though the mean age-dependent SDS was significantly below normal: the majority of the surviving infants were impaired (Fig. $5 b$ ). Hemorrhagic echodensities were frequently associated with low $\mathrm{PCr} / \mathrm{Pi}$ values and death or multiple impairments (Fig. $5 c$ ).

\section{DISCUSSION}

Methods for the absolute quantitation of phosphorus metabolites in tissue have only just become available (10). Therefore, 
Table 3. Age-dependent SDS for phosphorus metabolite ratios and $\mathrm{pH}_{i}$ in infants suspected of hypoxic-ischemic brain injury*

\begin{tabular}{lcccc}
\hline & $\begin{array}{c}\text { All infants } \\
(n=61)\end{array}$ & $\begin{array}{c}\text { Birth asphyxia } \\
(n=40)\end{array}$ & $\begin{array}{c}\text { Postnatal asphyxia } \\
(n=5)\end{array}$ & $\begin{array}{c}\text { Increased echodensities } \\
(n=16)\end{array}$ \\
\hline $\mathrm{PCr} / \mathrm{Pi}$ & $-2.14 \pm 2.10 \dagger$ & $-2.41 \pm 2.19 \dagger$ & $-0.03 \pm 0.76$ & $-2.04 \pm 1.78 \dagger$ \\
& & & & $-0.83 \pm 1.99$ \\
$\mathrm{ATP} /$ total P & $-0.98 \pm 1.86 \dagger$ & $-1.17 \pm 1.82 \dagger$ & $-0.01 \pm 1.03$ & $-2.19 \pm 2.52 \dagger$ \\
$\mathrm{PCr} /$ total P & $-1.72 \pm 2.58 \dagger$ & $-1.79 \pm 2.59 \dagger$ & $0.33 \pm 1.04$ & $5.51 \pm 9.06 \ddagger$ \\
$\mathrm{Pi} /$ total P & $5.40 \pm 8.77 \dagger$ & $5.97 \pm 8.91 \dagger$ & $0.69 \pm 0.99$ & $0.30 \pm 1.83$ \\
PME/total P & $0.42 \pm 1.69$ & $0.63 \pm 1.58$ & $-0.79 \pm 1.26$ & $-0.32 \pm 1.47$ \\
PDE/total P & $0.44 \pm 1.43$ & $-0.60 \pm 1.44 \S$ & $0.39 \pm 0.50$ & $0.31 \pm 2.91$ \\
& & & $0.15 \pm 0.66$ & $1.94 \pm 13.27 \ddagger$ \\
PCr/ATP & $0.52 \pm 2.98$ & $0.65 \pm 3.14$ & $0.35 \pm 1.06$ & $0.23 \pm 1.81$ \\
Pi/ATP & $7.21 \pm 16.41 \dagger$ & $8.96 \pm 17.94 \dagger$ & $-0.26 \pm 1.11$ & $0.00 \pm 2.21$ \\
PDE/ATP & $1.94 \pm 4.40 \S$ & $2.49 \pm 4.71 \ddagger$ & $0.17 \pm 0.77$ & $(n=14)$ \\
PDE/ATP & $1.02 \pm 3.84$ & $1.43 \pm 4.48$ & $-0.28 \pm 0.22$ & $(n=5)$ \\
\hline
\end{tabular}

* Values are those obtained when $\mathrm{PCr} / \mathrm{Pi}$ was at its lowest. Mean values for SDS \pm SD $v s$ the normal control infants are given.

$\dagger p<0.001$.

$\$ p<0.01$

$\S p<0.05$.
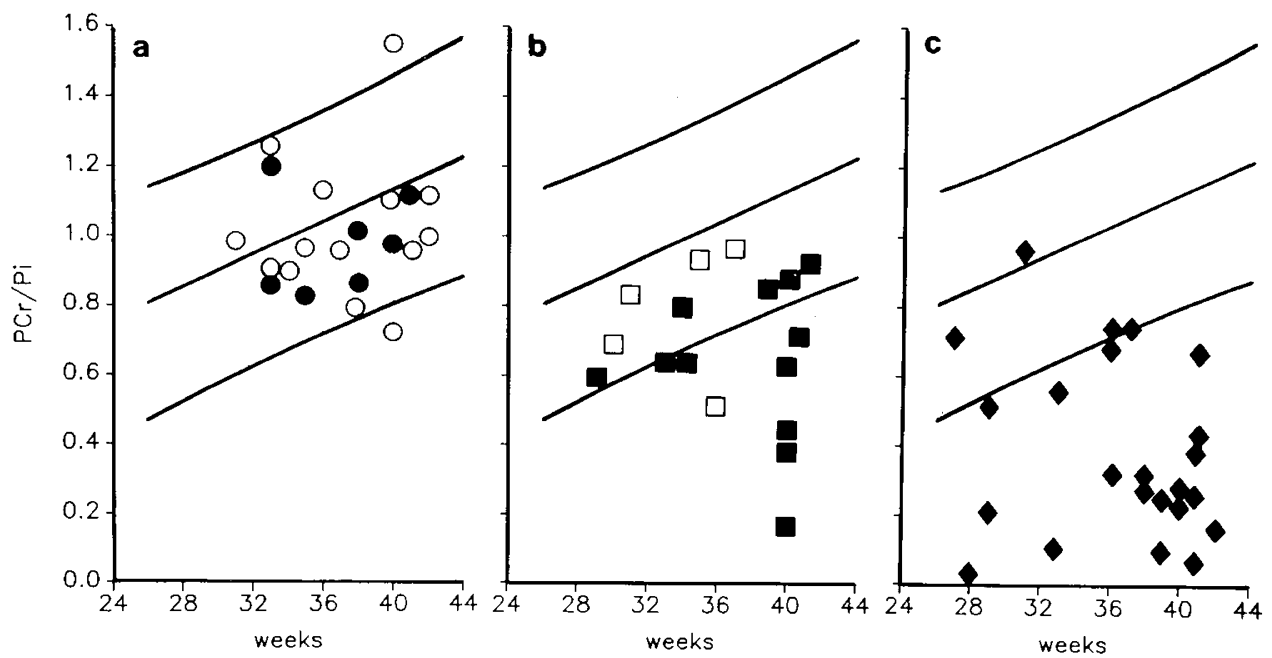

Fig. 2. Relation between minimum values for $\mathrm{PCr} / \mathrm{Pi}$, survival, and neurodevelopmental outcome aged $1 \mathrm{y}$. The regression line and $95 \%$ confidence limits for normal values $v$ s. gestational plus postnatal age are shown (6). $a, O=$ normal progress (SDS vs. normal infants, $-0.29 \pm \mathrm{SD}$ $1.21, \mathrm{NS}) ;-=$ minor impairments (SDS $-0.54 \pm 0.52, \mathrm{NS}$ ); $b, \square=$ major neuromotor impairment (SDS $-1.06 \pm 1.22, p<0.05$ ); $\mathbf{\square}=$ multiple major impairments (SDS $-2.60 \pm 1.44, p<0.001) ; c,=\operatorname{died}(\operatorname{SDS}-3.82 \pm 1.89, p<0.001)$.

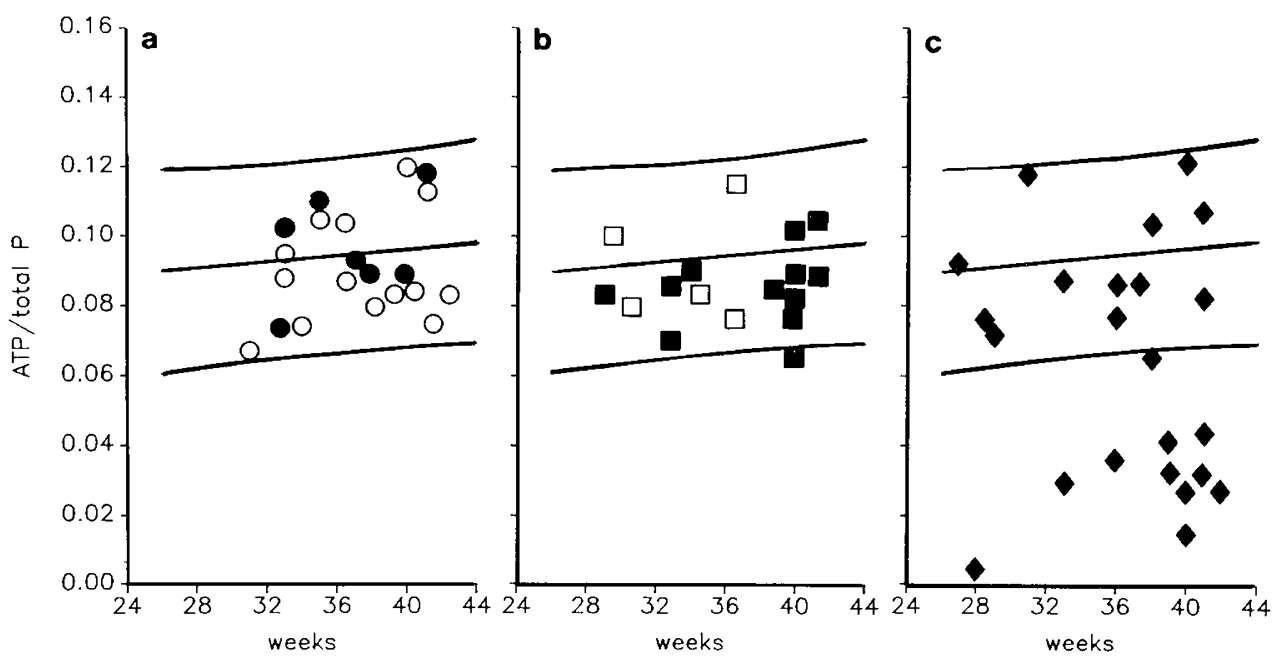

Fig. 3. Relation between values for ATP/total $\mathrm{P}$ when $\mathrm{PCr} / \mathrm{Pi}$ was at a minimum, survival, and neurodevelopmental outcome. The regression line and $95 \%$ confidence limits for normal values $v s$. gestational plus postnatal age are shown (6). $a, O=$ normal progress (SDS $v s$. normal infants, $-0.22 \pm \mathrm{SD} 1.01, \mathrm{NS}) ; \bullet=$ minor impairments (SDS $-0.03 \pm 0.98, \mathrm{NS}) ; b, \square=$ major neuromotor impairments (SDS $0.13 \pm 1.12, \mathrm{NS}$ ); $\mathbf{\square}=$ multiple major impairments (SDS $-0.67 \pm 0.74, p<0.05) ; c,=\operatorname{died}(\mathrm{SDS}-2.13 \pm 2.45, p<0.002$ ). 
in the present study, as in previous ones, the spectral peak areas, which are proportional to concentration, were used to derive concentration ratios, and hence to obtain information about changes in metabolites that are involved in oxidative phosphorylation (1-6).

Sequence of changes in phosphorus metabolites. Previous MRS investigations in adult and newborn animals have shown that acute cerebral hypoxemia or ischemia initially causes reciprocal changes in the concentrations of $\mathrm{PCr}$ and $\mathrm{Pi}$, so that the $\mathrm{PCr} / \mathrm{Pi}$ ratio falls $(11-14)$. Only when $\mathrm{PCr} / \mathrm{Pi}$ reaches a low value does the concentration of ATP in the tissue decline appreciably. These findings are to be expected from consideration of the creatine kinase reaction; $\mathrm{PCr}$ buffers any tendency of ATP to fall when oxidative phosphorylation becomes inadequate. At the same time as the changes in phosphorus metabolites, $\mathrm{pH}_{\mathrm{i}}$ falls to a low level, due to anaerobic glycolysis and the production of lactic acid (14). After a severe acute hypoxic-ischemic insult, recovery of the phosphorus metabolite concentrations and $\mathrm{pH}_{\mathrm{i}}$ can be complete within about $1 \mathrm{~h}(13,14)$.

We have previously shown that birth-asphyxiated babies commonly had normal phosphorus spectra and values of $\mathrm{pH}_{\mathrm{i}}$ on the

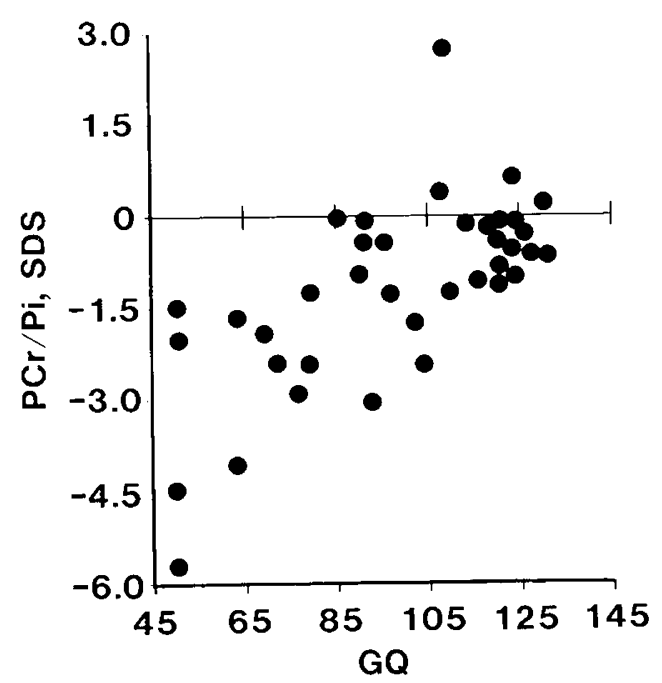

Fig. 4. Relation between minimum values for $\mathrm{PCr} / \mathrm{Pi}$ expressed as SDS vs. normal infants (6) and GQ at $1 \mathrm{y}$ in the 38 survivors. Scores of 50 or below are recorded as $50(r=0.67, p<0.001)$. 1st $\mathrm{d}$ of life, but that abnormalities appeared over the subsequent few $d(3)$. These abnormalities developed in spite of satisfactory arterial oxygen and carbon dioxide tensions and $\mathrm{pH}$, and blood glucose levels. They were initially similar to those encountered during acute hypoxia or ischemia, with roughly reciprocal changes in PCr and Pi and, in severely affected infants, a fall in $\mathrm{ATP} /$ total $\mathrm{P}$. However, $\mathrm{pH}_{\mathrm{i}}$ tended to rise, rather than fall. Later, $\mathrm{Pi}$ increased, well out of proportion to the fall in $\mathrm{PCr}$, and in severely damaged brains, PCr and ATP were absent, leaving only a large residual $P i$ peak in the spectrum $(4,15)$. In less severely affected infants who recovered, the phosphorus metabolite ratios returned to normal over the course of about $2 \mathrm{wk}$, but sometimes the total phosphorus signal was reduced, indicating permanent loss of cells $(4,15)$. Similar sequences of events were encountered here, as illustrated in Figure 1. The explanation is likely to be that the initial acute hypoxic-ischemic episode initiated a series of reactions which later caused progressive disruption of oxidative phosphorylation in brain tissue. This disruption may be termed "secondary" energy failure. Damage to the mitochondrial respiratory electron transport chain due to calcium influx to cells and to the effects of free radicals and excitatory neurotransmitters may all have played a part and resulted in failure of utilization of available oxygen (15). Inadequacy of oxygen supply associated with cerebral edema and other factors is also likely to have been involved. It has been suggested that the observed sequence of changes may be interpreted in terms of metabolic heterogeneity of cells, and that the proportion of seriously compromised and dead cells may be estimated from the MRS data (16).

The data obtained in this study were entirely consistent with those previously found in infants with various forms of hypoxicischemic injury $(1,3,4,15-17)$. In particular, $\mathrm{PCr} / \mathrm{Pi}$ in infants studied primarily because of birth asphyxia and because of increased echodensities fell well below normal control values (Tables 2 and 3). The falls in $\mathrm{PCr} /$ total $\mathrm{P}$, and rises in $\mathrm{Pi} /$ total $\mathrm{P}$ and $\mathrm{Pi} / \mathrm{ATP}$, as well as the fall in $\mathrm{PCr} / \mathrm{Pi}$, were as expected, and the large and disproportionate increase in Pi relative to both total $\mathrm{P}$ and to ATP, when compared with the fall in $\mathrm{PCr}$, was consistent with the presence in brain tissue of a population of severely compromised cells. The finding that ATP/total $P$ was reduced also shows that oxidative phosphorylation was often very severely deranged. On average, $\mathrm{pH}_{\mathrm{i}}$ was slightly, though not significantly, raised. No significant changes were detected in the five infants studied primarily because of postnatal asphyxial episodes, even though they often had a substantial negative arterial BE subsequently (Table 1).
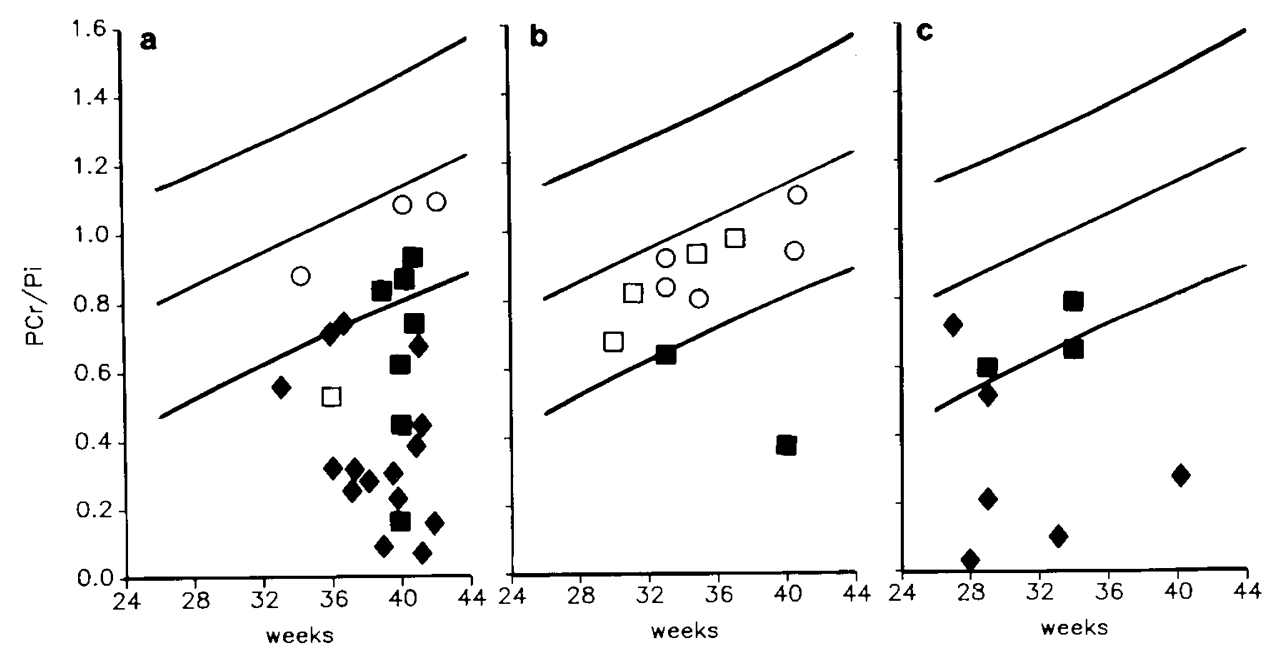

Fig. 5. Relation between minimum values for $\mathrm{PCr} / \mathrm{Pi}$ in infants with increased cerebral echodensities, survival, and outcome at $1 \mathrm{y}$. The regression line and $95 \%$ confidence limits for normal values $v s$. gestational plus postnatal age are shown (6). $a$, diffuse echodensities (SDS $v S$. normal infants $-3.35 \pm \mathrm{SD} 1.98, p<0.001) ; b$, periventricular echodensities suggestive of leukomalacia (SDS $-1.05 \pm 1.26, p<0.01$ ); $c$, dense echodensities attributed to intraparenchymal hemorrhage (SDS $-2.97 \pm 1.83, p<0.001$ ). $\mathrm{O}=$ no, or minor impairments; $\square=$ major neuromotor impairment; $=$ multiple major impairments; $\bullet$ died. 
The PME peak in the phosphorus spectrum is attributable mainly to phosphoethanolamine (18), a major precursor of membrane phospholipid and myelin, and the PDE peak contains phosphatidylethanolamine and phosphatidylcholine (22), important components of membranes and myelin. The only change in other metabolites relative to these "fixed" components of cells of more than borderline statistical significance was the increase in PME/ATP in birth-asphyxiated babies (Table 3). This change was attributable to the reduction in ATP.

Prognostic significance of changes in phosphorus metabolites. For the purposes of relating the changes in metabolite ratios to outcome, the maximum detected reduction in $\mathrm{PCr} / \mathrm{Pi}$ was selected as the most appropriate metabolic marker, because the results of previous work $(1,3,4,15,17)$ suggested that this value would reflect severe interference with oxidative phosphorylation, causing both a shift in the creatine kinase equilibrium and also a superimposed component of Pi derived from seriously compromised cells. The significance of ATP/total P at the time when $\mathrm{PCr} / \mathrm{Pi}$ was minimal was also investigated as a predictor of outcome, because of the likelihood that a reduction in this value would be of particularly serious prognostic significance.

For assessing neurodevelopmental outcome, the infants were classified into four groups. The first two groups comprised those who were normal or who had only minor impairments: as defined, the latter have been shown not to lead to gross neuromotor disabilities later-though they may indicate an increased likelihood of cognitive deficits or impairments of fine motor skills, or coordination, at 4 y of age (19). The third group included infants with isolated but serious neuromotor impairments (cerebral movement disorders); and the fourth group, infants who had multiple impairments. These latter infants were all extremely severely disabled, usually with tetraplegia, developmental delay, and often microcephaly.

The data presented in Figures 2 and 4 show clearly that the lower the value for $\mathrm{PCr} / \mathrm{Pi}$, the worse the outlook. Infants found to be progressing normally or with minor impairments had values that were usually normal (Fig. 2a), as did infants with purely neuromotor impairments (Fig. $2 b$ ). By contrast, infants found to have multiple impairments (Fig. 2b), or those who died (Fig. 2c) generally had low values for $\mathrm{PCr} / \mathrm{Pi}$. The sensitivity of identification by low $\mathrm{PCr} / \mathrm{Pi}$ of infants who were subsequently found to have multiple impairments or who died was $74 \%$, the specificity was $92 \%$, and the positive predictive value was $93 \%$. Figure 4 shows that the lower the $\mathrm{PCr} / \mathrm{Pi}$ ratio, the lower the $\mathrm{GQ}$ was subsequently found to be. Figure 3 shows that when low values for ATP/total P were found, death almost always ensuedbecause of very severe energy failure. The sole survivor had extremely serious multiple impairments. The sensitivity of identification by low ATP/total P of infants who subsequently died was $47 \%$, the specificity was $97 \%$, and the positive predictive value was $91 \%$.

We believe that the positive predictive values of low $\mathrm{PCr} / \mathrm{Pi}$ and low ATP/total P for death or very severe disability were so high that they may in the future be taken into account when decisions are made about how far intensive care should be pursued in infants with hypoxic-ischemic brain injury.

Increased echodensities and changes in phosphorus metabolites. We have previously shown that when increased cerebral echodensities were associated with falls in $\mathrm{PCr} / \mathrm{Pi}$, death or loss of brain tissue in survivors were almost certain (4). In that study, no distinction was made between different types of echodensities. In the present study, some infants were studied primarily because of increased echodensities, and many other infants studied primarily because of birth asphyxia also developed echodensities. To investigate the relation between the type of echodensities, $\mathrm{PCr} / \mathrm{Pi}$ and outcome, all infants with increased echodensities were classified into one of three groups: those whose echodensities were widespread and diffuse, those with echodensities thought characteristic of PVL, and those with very dense echodensities characteristic of intraparenchymal cerebral hemorrhage due either to bleeding into areas of PVL or to venous infarction (5). The finding that infants with diffuse echodensities usually had low values for PCr/Pi and fared extremely badly (Fig. 5a) demonstrates that these echodensities generally reflected widespread severe disruption of energy metabolism. Infants with echodensities thought to be attributable to PVL usually had values for $\mathrm{PCr} / \mathrm{Pi}$ within normal limits, but were often found to be neurologically impaired at follow-up (Fig. $5 b$ ). As the phosphorus spectra were obtained mainly from the cerebral cortex (20), it is highly likely that evidence of localized abnormal metabolism deep in the brains of these infants was missed. With improvements in the methodology of MRS, whereby spectra can be acquired from selected regions of the brain, it will in the future be possible to obtain more detailed information about localized lesions such as PVL. The low values for $\mathrm{PCr} / \mathrm{Pi}$ and bad outcome associated with intraparenchymal hemorrhage (Fig. 5c) are consistent with the markedly reduced blood flow found by positron emission tomography in similarly affected hemispheres by Volpe et al. (21).

Acknowledgments. The authors are grateful to R. Aldridge, Dr. A. D. Edwards, E. Eldon, Dr. S. J. Gould, Prof. D. R. Wilkie, Dr. Susan Wray, and the staff of the Neonatal Unit, the Children's Outpatient Department, and the Department of Medical Physics and Bioengineering, for their help with this study; and to Mrs. Grace Harris for preparing the manuscript.

\section{REFERENCES}

1. Cady EB, Costello AM deL, Dawson MJ, Delpy DT, Hope PL, Reynolds, EOR, Tofts PS, Wilkie DR 1983 Non-invasive investigation of cerebral metabolism in newborn infants by phosphorus nuclear magnetic resonance spectroscopy. Lancet 1:1059-1062

2. Younkin DP, Delivoria-Papadopolous M, Leonard J, Subramanian VH, Eleff S, Leigh JS, Chance B 1984 Unique aspects of human cerebral metabolism evaluated with phosphorus nuclear magnetic resonance spectroscopy. Ann Neurol 16:581-586

3. Hope PL, Costello AM deL, Cady EB, Deply DT, Tofts PS, Chu A, Hamilion PA, Reynolds EOR, Wilkie DR 1984 Cerebral energy metabolism studied with phosphorus NMR spectroscopy in normal and birth-asphyxiated infants. Lancet 2:366-370

4. Hamilton PA, Hope PL, Cady EB, Delpy DT, Wyatt JS, Reynolds EOR 1986 Impaired energy metabolism in brains of newborn infants with increased cerebral echodensities. Lancet 1:1242-1246

5. Hope PL, Gould SJ, Howard S, Hamilton PA, Costello AM deL, Reynolds EOR 1988 Precision of ultrasound diagnosis of pathologically verified lesions in the brains of very preterm infants. Dev Med Child Neurol 30:457-471

6. Azzopardi D, Wyatt JS, Hamilton PA, Cady EB, Delpy DT, Hope PL, Reynolds EOR Phosphorus metabolites and intracellular $\mathrm{pH}$ in the brains of normal and small for gestational age infants investigated by magnetic resonance spectroscopy. Pediatr Res 25:440-444

7. Petroff OAC, Prichard JW, Behar KL, Alger JR, den Hollander JA, Shulman RG 1985 Cerebral intracellular $\mathrm{pH}$ by $31 \mathrm{P}$ magnetic resonance spectroscopy. Neurology 35:781-788

8. Stewart AL, Thorburn RJ, Hope PL, Goldsmith M, Lipscomb AP, Reynolds EOR 1983 Ultrasound appearance of the brain in very preterm infants and neurodevelopmental outcome at 18 months of age. Arch Dis Child 58:598604

9. Griffiths R 1954 The Abilities of Babies. University of London Press, London

10. Tofts PS, Wray S 1988 Non-invasive measurements of molar concentrations of $31 \mathrm{P}$ metabolites in vivo using surface coil NMR spectroscopy. Mag Res Med 6:84-86

11. Delpy DT, Gordon RE, Hope PL, Parker D, Reynolds EOR, Shaw D, Whitehead MD 1982 Non-invasive detection of cerebral ischemia by phosphorus nuclear magnetic resonance. Pediatrics 70:310-313

12. Prichard JW, Alger JR, Behar KL, Petroff OAC, Shulman RG 1983 Cerebral metabolic studies in vivo by $31 \mathrm{P}$ NMR. Proc Natl Acad Sci USA 80:27482751

13. Hope PL, Cady EB, Chu A, Delpy DT, Gardiner RM, Reynolds EOR 1987 Brain metabolism and intracellular pH during ischaemia and hypoxia: an in vivo $31 \mathrm{P}$ and $1 \mathrm{H}$ nuclear magnetic resonance study in the lamb. J Neurochem 49:75-82

14. Laptook AR, Corbett RJT, Nguyen HT, Peterson J, Nunnally RL 1988 Alterations in cerebral blood flow and phosphorylated metabolites in piglets during and after partial ischemia. Pediatr Res 23:206-211

15. Reynolds EOR, Wyatt JS, Azzopardi D, Delpy DT, Cady EB, Cope M, Wray S 1988 New non-invasive methods for assessing brain oxygenation and haemodynamics. Br Med Bull 44:1052-1075 
16. Chance B, Leigh JS, Nioka S, Sinwell T, Younkin D, Smith D 1987 An approach to the problem of metabolic heterogeneity in brain: ischemia and reflow after ischemia. Ann New York Acad Sci 508:309-319

17. Delpy DT, Cope MC, Cady EB, Wyatt JS, Hamilton PA, Hope PL, Wray S, Reynolds EOR 1987 Cerebral monitoring in newborn infants by magnetic resonance and near infrared spectroscopy. Scand J Clin Lab Invest 47 suppl 188:9-17

18. Gyulai L, Bolinger L, Leigh JS, Barlow C, Chance B 2984 Phosphorylethanolamine-the major constituent of phosphomonoester peak observed by 31PNMR in developing dog brain. FEBS Lett 178:137-142

19. Costello AM deL, Hamilton PA, Baudin J, Townsend J, Bradford BC, Stewart AL, Reynolds EOR 1988 Prediction of neurodevelopmental impairment at
4 years from brain ultrasound appearance in very preterm infants. Dev Med Child Neurol. 30:711-722

20. Tofts $P 1986$ Tissue localization in surface coil nuclear magnetic resonance (NMR) spectroscopy. In: Rolfe P (ed) Fetal and Neonatal Physiological Measurements. Butterworths, London, pp 363-372

21. Volpe JJ, Herscovitch P, Perlman JM, Raichle ME 1983 Positron emission tomography in the newborn: extensive impairment of regional cerebral blood flow with intraventricular hemorrhage and hemorrhagic intracerebral involvement. Pediatrics 72:589-601

22. Cerdan S, Subramanian H, Hilberman M, Core J, Egan J, Chance B, Williamson JR $1986^{31} \mathrm{P}$ NMR detection of mobile dog brain phospholipids. Mag Res Med 3:432-439 